\title{
Release of arachidonic acid from human endometrial cells in culture mediated by calcium ionophore (A23187) or fluoride
}

\author{
R. C. Bonney ${ }^{1}$, J. S. Beesley ${ }^{1}$ and S. Franks ${ }^{2}$ \\ Departments of ${ }^{1}$ Chemical Pathology and ${ }^{2}$ Obstetrics and Gynaecology, St Mary's Hospital \\ Medical School, London W2 IPG, UK
}

\begin{abstract}
Summary. Primary cultures of endometrial glands and stromal cells were labelled with $\left[{ }^{14} \mathrm{C}\right]$-arachidonic acid for $4 \mathrm{~h}$ before exposure to either the calcium ionophore, A23187 (which activates phospholipase $\mathrm{A}_{2}\left(\mathrm{PLA}_{2}\right)$ by increasing intracellular calcium concentrations) or sodium fluoride (which activates a G-protein). Calcium ionophore $(0 \cdot 5-$ $50 \mu \mathrm{mol} / \mathrm{l}$ ) stimulated a dose- and time-dependent release of arachidonic acid from endometrial glands. Incubation with ionophore $(10 \mu \mathrm{mol} / 1)$ for $1 \mathrm{~h}$ released $22 \%$ of the incorporated arachidonic acid. There was a corresponding decrease in phospholipids and no loss from triglycerides. Stromal cells were unresponsive to ionophore. Fluoride $(10 \mathrm{mmol} / \mathrm{l})$ stimulated a release of arachidonic acid from stromal cells and endometrial glands (6.5\% of the total arachidonic acid incorporated). In stromal cells, arachidonic acid was released from triglycerides in Day-1 cultures and from phospholipids in Day-2 cultures. In both Day-1 and Day-2 cultures of endometrial glands, arachidonic acid was released from phospholipids, but not from triglycerides. Among the phospholipids, phosphatidylcholine was always the major source of arachidonic acid.

Arachidonic acid release from endometrial glands and stromal cells may be mediated by activation of PLA $_{2}$ (or phospholipase C) via a G-protein, but in glands calcium ionophore may have a direct effect on PLA $\mathbf{P}_{2}$. The response to calcium ionophore may reflect the differences in calcium requirements of the two endometrial $\mathrm{PLA}_{2}$ isoenzymes.
\end{abstract}

Keywords: endometrium; arachidonic acid; phospholipase $\mathrm{A}_{2}$; triglycerides; phospholipids; human

\section{Introduction}

Activation of phospholipase $\mathrm{A}_{2}$ (PLA $\mathrm{P}_{2}$; phosphatide 2-acylhydrolase, E.C.3.1.1.4) leads to the hydrolysis of membrane phospholipids, the liberation of free arachidonic acid and the subsequent generation of eicosanoids and other arachidonic acid metabolites. Cytoplasmic calcium concentrations have long been proposed as the primary regulator of PLA $\mathrm{P}_{2}$ activity, supported by the evidence that, in many tissues, calcium is required for enzyme activation (van den Bosch, 1980). However, an increasing number of calcium-independent $\mathrm{PLA}_{2}$ enzymes have been described (Vadas \& Pruzanski, 1986), suggesting that the presence of calcium may not be obligatory for PLA 2 activation.

Our studies have shown that human endometrium contains two PLA 2 isoenzymes: a calciumdependent enzyme in the glandular component of the endometrium, the activity of which increases in the secretory phase of the menstrual cycle (PLA $\mathrm{P}_{2}$ type 1 ), and a calcium-independent enzyme of stromal cell origin (PLA $\mathrm{PL}_{2}$ type 2) (Bonney et al. 1987). The activity of PLA $\mathrm{A}_{2}$ type 2 is not apparently related to the stage of the menstrual cycle, but increases in proliferative-phase endometrium of women with polycystic ovaries (Bonney \& Franks, 1990). Further differences in the two isoenzymes 
lie in the $\mathrm{pH}$ requirements; $\mathrm{PLA}_{2}$ type 1 has a broader optimum $\mathrm{pH}$ range of $7 \cdot 5-9 \cdot 0$, whereas $\mathrm{PLA}_{2}$ type 2 is optimally active at $\mathrm{pH} 6 \cdot 5-7 \cdot 0$. The different characteristics of these two enzymes suggest that they may be regulated by different mechanisms, one dependent on the presence of intracellular calcium ions and the other not.

The present study investigated the mechanisms involved in the activation of endometrial phospholipases and the regulation of release of arachidonic acid. We report here the effect of two stimulators of $\mathrm{PLA}_{2}$ activity, calcium ionophore (A23187) and sodium fluoride, on the release of arachidonic acid from endometrial glands and stromal cells in primary culture. The calcium ionophore A23187 activates PLA $_{2}$ in many cell types by facilitating calcium transport across the extracellular membrane, thus permitting an influx of extracellular calcium. Stimulation of PLA activity by fluoride ions is mediated via a G-protein and may not require calcium ions. The present study was designed to clarify the mechanisms involved in regulating the activity of the calciumdependent and calcium-independent PLA P $_{2}$ isoenzymes of human endometrium.

\section{Materials and Methods}

Materials. All reagents except culture media were, unless otherwise stated, obtained from the Sigma Chemical Co. Ltd, Poole UK. Culture media and fetal calf serum were obtained either from Flow Laboratories Ltd, Rickmansworth, Herts, WD3 1PQ, UK, or from Gibco Ltd, Paisley, UK. Multiwell plates were manufactured by 'Linbro' and obtained from Flow Laboratories Ltd. $\left[{ }^{14} \mathrm{C}\right]-$ Arachidonic acid (sp. act. $50-60 \mathrm{mCi} / \mathrm{mmol}$ or $1 \cdot 85-2 \cdot 2 \mathrm{GBq} / \mathrm{mmol}$ ) was purchased from Amersham International plc, Bucks, UK. It was stored under nitrogen at $-20^{\circ} \mathrm{C}$ to ensure minimal oxidation and used within 1 month of purchase.

Collection of endometrium. Endometrium was obtained in the operating theatre from premenopausal women who were undergoing hysterectomy for reasons unassociated with malignancy. The study was approved by the local ethics committee (Parkside Health Authority). A portion of endometrium was sent to the pathology laboratory for histopathological assessment. The remaining tissue was transported to the laboratory on ice in a sterile container in Hank's balanced salt solution (HBSS) containing kanamycin $(0.1 \mathrm{mg} / \mathrm{ml})$ and nystatin $(10 \mathrm{U} / \mathrm{ml})$. The results of the study were not influenced by the stage of the cycle and therefore proliferative and secretory-phase tissues were used. If an abnormality was reported after histopathological examination, the data were not included in the study.

Dispersion. The tissue was washed twice with HBSS and chopped finely with scissors. It was then incubated at $37^{\circ} \mathrm{C}$ for $3040 \mathrm{~min}$ in $15 \mathrm{ml}$ HBSS containing $0.25 \%$ collagenase (Type 1) and $0.1 \%$ DNase. During the course of the incubation the vessel was agitated periodically to facilitate dispersion. The final stage of the dispersion was carried out using a $1 \mathrm{ml}$ pipette to aspirate the contents of the vessel 10-20 times. The dispersed tissue was then filtered through wire gauze ( $100 \mu \mathrm{m}$ mesh size, obtained from R. Cadisch \& Son, Arcadia Avenue, Finchley, London N3 $2 \mathrm{JZ}$, UK) to remove any remaining particles of tissue. A further $25 \mathrm{ml}$ HBSS was passed through the mesh to wash through adhering cells or glands and the combined filtrates centrifuged at $250 \mathrm{~g}$ for $5 \mathrm{~min}$ at $4^{\circ} \mathrm{C}$. The pellet was washed twice with HBSS and then resuspended in $5 \mathrm{ml}$ HBSS. The suspension was then filtered through a $38-\mu \mathrm{m}$ wire gauze to separate endometrial glands from stromal cells. The stromal cell preparation contained all the cell types within the endometrium, except glands, although some contamination from fragmented glands may also have occurred. The preparation was therefore, in effect, an enriched stromal cell preparation. The filtration was completed by washing the glands remaining on the gauze with $15 \mathrm{ml}$ HBSS. The glands were then backwashed into a Petri dish with Ham's F10 Hepes-buffered medium supplemented with $5 \%$ fetal calf serum, $2 \mathrm{mmol}$ glutamine $/ 1,5 \mu \mathrm{g}$ insulin $/ \mathrm{ml}$ and $0.1 \mathrm{mg}$ kanamycin/ml. Separated glands and stromal cells were centrifuged for $5 \mathrm{~min}$ at $250 \mathrm{~g}$, resuspended in Ham's F10 medium containing serum (supplemented as above) and plated out into 24-well plates at $2 \times 10^{5}$ stromal cells per well (plated initially in $0.5 \mathrm{ml}$ medium). The glands were distributed evenly to half the number of wells prepared for the stromal cells. Consistent plate coverage and consistent results were obtained by this procedure.

After attachment (routinely $24 \mathrm{~h}$ later) the cells were washed with HBSS to remove blood cells and other debris and incubation was continued for a minimum of $24 \mathrm{~h}$ in fresh Ham's F10 medium. The cells were used for experimental procedures $1-3$ days after attachment.

Experimental procedures. The cells were washed three times with saline. They were then labelled with $\left[{ }^{14} \mathrm{C}\right]-$ arachidonic acid $(0.1 \mu \mathrm{Ci}(3.7 \mathrm{kBq}) /$ well $)$ contained in $0.5 \mathrm{ml}$ Ham's $\mathrm{F} 10$ bicarbonate-buffered, low-phenol-red medium supplemented with $2 \mathrm{mmol}$ glutamine $/ \mathrm{l}$ and $0 \cdot 1 \%$ bovine serum albumin (BSA). The concentration of radiolabelled arachidonic acid was $3.3 \mathrm{nmol} / 1$. It was prepared in ethanol and diluted with medium such that the final concentration of ethanol was $0.4 \%$ per well. Incubation was carried out for $4 \mathrm{~h}$ at $37^{\circ} \mathrm{C}$ in a humidified atmosphere of $95 \%$ air and $5 \% \mathrm{CO}_{2}$. An incubation period of $4 \mathrm{~h}$ was selected to permit adequate incorporation of radioactivity and to be within the period of rapid turnover of the lipid pools. The labelled cells were washed three times with Ham's F10 after which the appropriate treatments $\left(\mathrm{Ca}^{2+}\right.$ ionophore, or fluoride) were added in $0.2 \mathrm{ml}$ Ham's F10 medium 


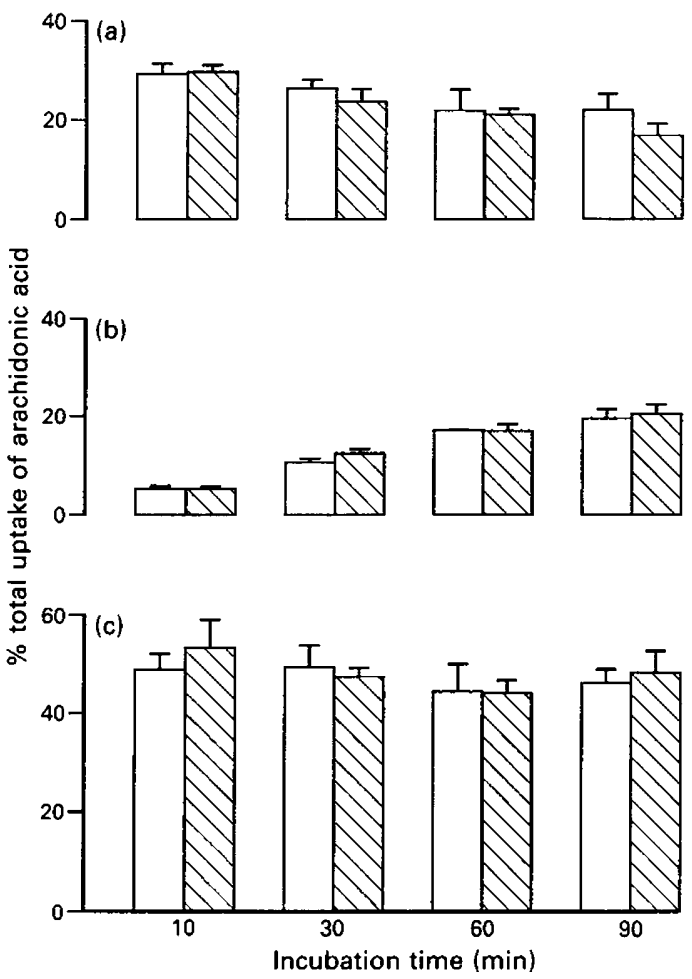

Fig. 1. Effect of incubation time on the release of $\left[{ }^{14} \mathrm{C}\right]$-arachidonic acid from prelabelled human endometrial stromal cells in culture, incubated in the absence $(\square)$ or presence $(\mathbb{\nabla})$ of $10 \mu \mathrm{mol}$ calcium ionophore (A23187)/1. Uptake into (a) triglycerides and (c) phospholipids and (b) release of free arachidonic acid is expressed at $\%$ total $\left[{ }^{14} \mathrm{C}\right]$-arachidonic acid incorporated during a 4-h prelabelling period. Each bar represents the mean \pm s.d. of 4 replicates.

(bicarbonate-buffered, low-phenol-red, supplemented with 2 mmol glutamine/l) $+0.5 \%$ BSA. The control wells contained ethanol as appropriate to the treatment used in the study. Incubation was continued for $1 \mathrm{~h}$ unless otherwise stated.

Termination of incubation. At the end of the incubation period, the medium was removed to a glass tube containing $0.5 \mathrm{ml}$ methanol. A further $0.5 \mathrm{ml}$ methanol was added to each well and left to incubate at room temperature for $1 \mathrm{~h}$ to extract the lipids. This fraction was then transferred to the same tube with two further methanol washes to give a final methanol extract volume of $2 \mathrm{ml}$.

Extraction of lipids. The methanol fraction was vortexed with $2 \mathrm{ml}$ chloroform followed by $2 \mathrm{ml} 2 \mathrm{~mol} \mathrm{KCl} / \mathrm{l}$ and $5 \mathrm{mmol}$ EDTA/1. Efficient separation of the chloroform and methanol layers was achieved by centrifugation at $600 \mathrm{~g}$ for $10 \mathrm{~min}$ and $2 \times 0.95 \mathrm{ml}$ chloroform layer was then removed for thin-layer chromatography (TLC) of neutral lipids and phospholipids. The efficiency of this extraction procedure in initial studies was invariably $100 \%$.

Separation and quantification of cell lipids. Neutral lipids were separated by TLC using the system hexane:diethyl ether:formic acid (80:50:6 by volume) with a development time of $1 \mathrm{~h}$. The TLC plates used were silica gel, $0.2 \mathrm{~mm}$ thick (from E. Merck, Darmstadt, Germany). Neutral lipid standards, $25 \mu \mathrm{g}$ each of arachidonic acid, triglyceride (trilinolein) and in initial experiments, 1,2 and 1,3 diglycerides (diolein) and monoglyceride (monoolein) were added prior to separation. The lipid bands were identified by exposure to iodine vapour. The $\mathrm{R}_{\mathrm{F}}$ values for the lipids isolated in this system were: triglycerides, 0.83 ; arachidonic acid, $0.53 ; 1,3$-diaglyceride, $0.33 ; 1,2$-diglyceride, 0.28 ; and monoglyceride, 0.073 . The incorporation of $\left[{ }^{4} \mathrm{C}\right]$-arachidonic acid into the various lipid fractions was determined by scraping the identified areas into scintillation vials containing $5 \mathrm{ml}$ Ecoscint (National Diagnostics, Aylesbury, Bucks, UK) and measuring radioactivity with a Beckman LS7500 scintillation counter. The efficiency for carbon under these conditions was $93 \%$. Phospholipids were separated by TLC using the system chloroform:methanol:acetic acid:0.1 mol sodium borate/1: (75:45:12:4.5 by volume) with a development time of $1 \mathrm{~h} 20 \mathrm{~min}$. Phospholipid standards ( $25 \mu \mathrm{g}$ each of phosphatidylethanolamine (PE), phosphatidylcholine (PC) and phosphatidylinositol (PI)) were added to each sample prior to separation and the phospholipid bands were identified and radioactivity was measured as described. The $R_{F}$ values for the phospholipids identified in this system were: phosphatidylethanolamine, $0 \cdot 70$; phosphatidylinositol, $0 \cdot 47$; and phosphatidylcholine, $0 \cdot 27$. 


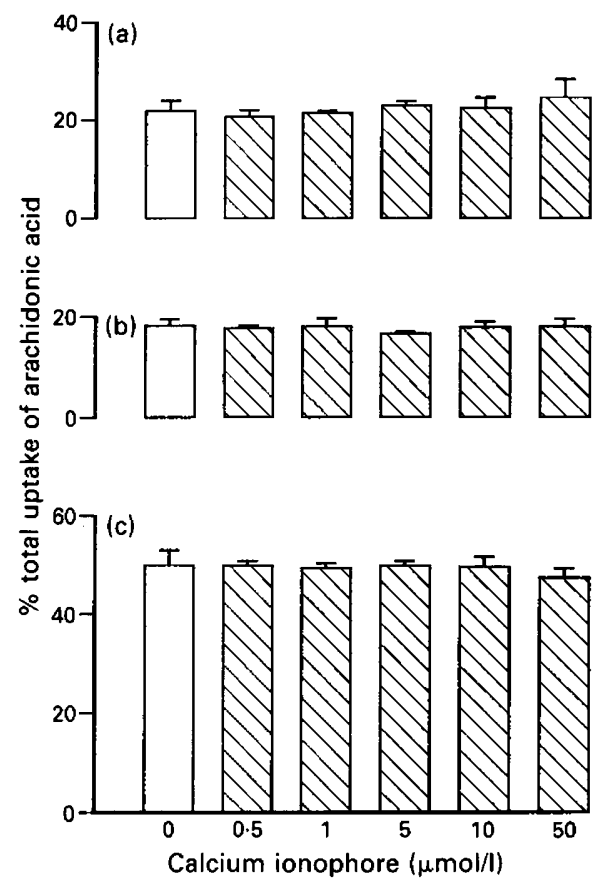

Fig. 2. Release of $\left[{ }^{14} \mathrm{C}\right]$-arachidonic acid from prelabelled human endometrial stromal cells in culture after incubation for $1 \mathrm{~h}$ in the absence $(\square)$ or presence $(\mathbb{N})$ of $0.5-50 \mu \mathrm{mol}$ calcium ionophore (A23187)/l. Uptake into (a) triglycerides and (c) phospholipids and (b) release of free arachidonic acid is expressed as $\%$ total $\left[{ }^{14} \mathrm{C}\right]$-arachidonic acid incorporated during a 4-h prelabelling period. Each bar represents the mean \pm s.d. of 4 replicates.

Calculation of results. The incorporation of $\left[{ }^{14} \mathrm{C}\right]$-arachidonic acid into the respective lipid fractions and the amount released into the medium was expressed as a percentage of the total amount incorporated per well. Under the experimental conditions used, arachidonic acid metabolites were not detectable. Total incorporation of $\left[{ }^{14} \mathrm{C}\right]-$ arachidonic acid was calculated by measuring radioactivity in an aliquant of chloroform extract from each well prior to TLC. The amount of $\left[{ }^{14} \mathrm{C}\right]$-arachidonic acid recovered from the TLC plate was routinely $75-85 \%$ of the total radioactivity incorporated per well. Each treatment was conducted in quadruplicate and the data were analysed by one-way ANOVA and unpaired $t$ test. Each experiment was carried out a minimum of three times and the data presented are typical of those obtained on each occasion.

\section{Results}

\section{Effect of calcium ionophore on release of arachidonic acid}

Stromal cells in culture. Stromal cells were prelabelled with $\left[{ }^{14} \mathrm{C}\right]$-arachidonic acid for $4 \mathrm{~h}$ and then incubated for $10-90 \mathrm{~min}$ in the presence or absence of $10 \mu \mathrm{mol}$ calcium ionophore/1. During incubation in the absence of calcium ionophore, there was a linear increase in the release of arachidonic acid from $5 \%$ (of the total $\left[{ }^{14} \mathrm{C}\right]$-arachidonic acid incorporated at prelabelling) at $10 \mathrm{~min}$ to $19 \%$ at $90 \mathrm{~min}$ (Fig. 1). The release occurred mainly from the triglyceride pool, which was reduced from $29 \%$ at $10 \mathrm{~min}$ to $22 \%$ at $90 \mathrm{~min}$. The radiolabelled phospholipids, which accounted for $49 \%$ of the total arachidonic acid incorporated at $10 \mathrm{~min}$, decreased after 60 and $90 \mathrm{~min}$ of incubation to 44 and $46 \%$, respectively. Addition of calcium ionophore to the incubation medium had no effect on arachidonic acid release irrespective of the incubation time. None of the concentrations of ionophore tested was effective in stimulating a release of arachidonic acid (Fig. 2). 

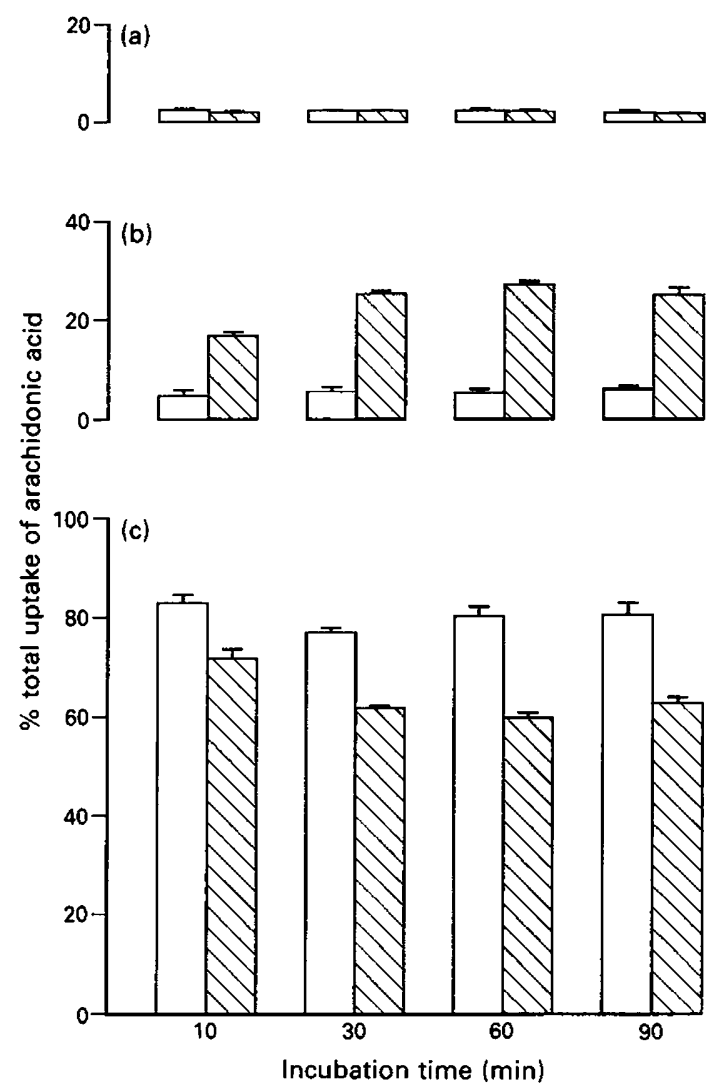

Fig. 3. Time course of $\left[{ }^{14} \mathrm{C}\right]$-arachidonic acid release from prelabelled human endometrial glands in culture, in the absence $(\square)$ or presence $(\mathbb{\nabla})$ of $10 \mu$ mol calcium ionophore (A23187)/l. Uptake into (a) triglycerides and (c) phospholipids and (b) release of free arachidonic acid is expressed as \% total $\left[{ }^{14} \mathrm{C}\right]$-arachidonic acid incorporated during a 4 -h prelabelling period. Each bar represents the mean \pm s.d. of 4 replicates.

Incorporation of $\left[{ }^{14} \mathrm{C}\right]$-arachidonic acid into diglycerides represented only $1-2 \%$ of total incorporation and $<1 \%$ was present in monoglycerides. These lipid pools were unaffected by calcium ionophore.

Endometrial glands in culture. Similar experiments were conducted with endometrial glands. In contrast to stromal cells, uptake of $\left[{ }^{14} \mathrm{C}\right]$-arachidonic acid into triglycerides was minimal $(2 \%)$ and phospholipids accounted for $\sim 80 \%$ of the total $\left[{ }^{14} \mathrm{C}\right]$-arachidonic acid incorporated (Fig. 3). There was no basal release of arachidonic acid from triglycerides (or phospholipids) over the 10 $90 \mathrm{~min}$ of incubation. In the presence of calcium ionophore, however, there was a marked, timedependent release of arachidonic acid, the sole source of which was the phospholipid pool. The effect was maximal at $60 \mathrm{~min}$, when the release of arachidonic acid above the basal level (5\%) accounted for a further $22 \%$ of the total arachidonic acid incorporated. Expressed as c.p.m. released, this was equivalent to a basal release of $218 \pm 14$ c.p.m. and an ionophore-stimulated release of $1429 \pm 246$ c.p.m. Initially, phosphatidylinositol was the major source of liberated arachidonic acid, but with time the release of arachidonic acid from phosphatidylcholine became more important (Fig. 4). There was also a significant increase in uptake into phosphatidylethanolamine at $90 \mathrm{~min}(P<0.001)$ and this effect was seen in both the presence and absence of calcium ionophore, although in the latter case the effect was more marked. 


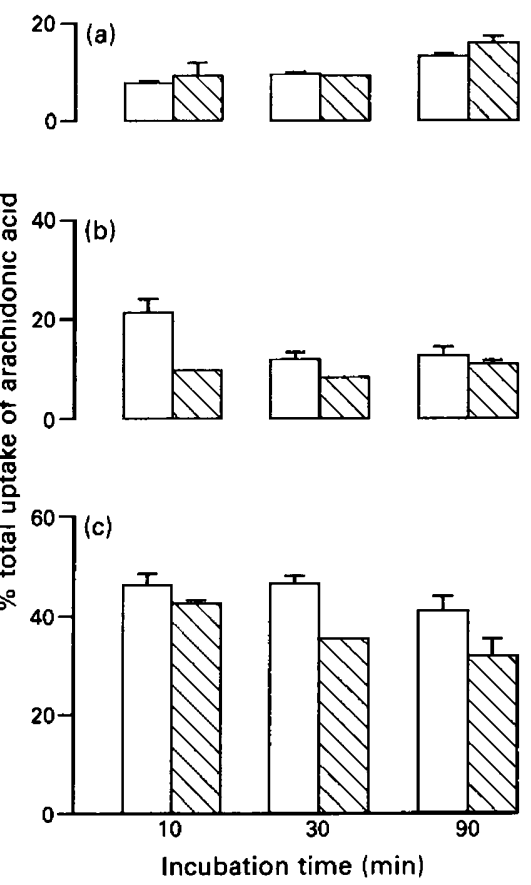

Fig. 4. Distribution of $\left[{ }^{14} \mathrm{C}\right]$-arachidonic acid between the major phospholipid pools following incubation of prelabelled human endometrial glands in culture, in the absence ( $\square$ ) or presence ( $\mathbb{N}$ ) of $10 \mu \mathrm{mol}$ calcium ionophore $(\mathrm{A} 23187) / \mathrm{l}$ for $10-90 \mathrm{~min}$. The figure shows uptake into (a) phosphatidylethanolamine (b) phosphatidylinositol and (c) phosphatidylcholine expressed as $\%$ total $\left[{ }^{14} \mathrm{C}\right]$-arachidonic acid incorporated during a 4-h prelabelling period and represents the total phospholipid pool from the experiment illustrated in Fig. 3. Each bar represents the mean \pm s.d. of 4 replicates.

The release of arachidonic acid from endometrial glands was dose related. Incubating prelabelled endometrial glands for $\mathrm{Ih}$ in the presence of $0.5-50 \mu \mathrm{mol}$ ionophore/l stimulated arachidonic acid release in a dose-dependent manner (Fig. 5). The lowest concentration of ionophore tested $(0.5 \mu \mathrm{mol} / \mathrm{l})$ stimulated a $5 \%$ release of arachidonic acid above the basal value (release in the absence of ionophore); in the presence of the highest concentration of ionophore tested $(50 \mu \mathrm{mol} / \mathrm{l})$ the release of arachidonic acid increased to $24 \%$ above the basal value. As demonstrated in the previous experiment, phospholipids were the source of the released arachidonic acid and (data not shown) phosphatidylcholine was the major phospholipid affected.

Incorporation of $\left[{ }^{14} \mathrm{C}\right]$-arachidonic acid into mono- and di-glycerides was $\sim 2-4 \%$ of the total incorporated and there was no effect of calcium ionophore on the distribution into these lipid pools.

\section{Effect of fluoride ions on the release of arachidonic acid}

Stromal cells in culture. In contrast to calcium ionophore, sodium fluoride stimulated a significant release of arachidonic acid from prelabelled stromal cells (Fig. 6). The response occurred after $60 \mathrm{~min}$ of incubation when a $7 \%$ release of arachidonic acid above the basal level (release in the absence of fluoride) was observed, i.e. 17 and $24 \%$ ( $3659 \pm 265$ and $5237 \pm 775$ c.p.m.) for basal and stimulated release, respectively. There was a further $2 \%$ release after $90 \mathrm{~min}$ of incubation (basal release: $4581 \pm 381$ c.p.m., fluoride-stimulated release: $6618 \pm 928$ c.p.m.). The phospholipid pool, more specifically phosphatidylcholine, was the source of the fluoride-stimulated release of arachidonic acid. The effect was more pronounced at $90 \mathrm{~min}$, when phosphatidylcholine 

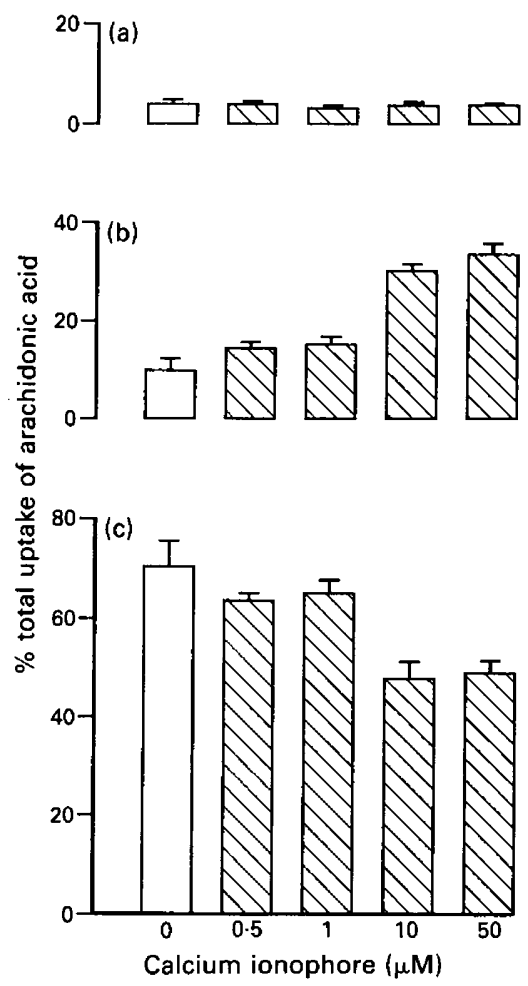

Fig. 5. Release of $\left[{ }^{14} \mathrm{C}\right]$-arachidonic acid from prelabelled human endometrial glands in culture following incubation for $1 \mathrm{~h}$ in the absence $(\square)$ or presence $(\mathbb{Q})$ of $0.5-50 \mu \mathrm{mol}$ calcium ionophore (A23187)/l. Uptake into (a) triglycerides and (c) phospholipids and (b) release of free arachidonic acid is expressed as $\%$ total $\left[{ }^{14} \mathrm{C}\right]$-arachidonic acid incorporated during a 4-h prelabelling period. Each bar represents the mean \pm s.d. of 4 replicates.

content of the cells decreased from $37.9 \pm 1.3$ to $29.4 \pm 0.9 \%$ total uptake $(P<0.001)$. Phosphatidylinositol was affected to a lesser extent; there was a small, but significant, decrease (from $8.8 \pm 0.7$ to $6 \cdot 6 \pm 0.2 \%$ total incorporation) in the $\left[{ }^{14} \mathrm{C}\right]$-arachidonic acid content of this phospholipid $(P<0.01)$. Phosphatidylethanolamine content was unaffected by fluoride ions in these experiments (data for phospholipids not shown).

The release of arachidonic acid from prelabelled endometrial stromal cells in response to fluoride ions differed depending on the number of days in culture prior to treatment. When the cells were treated on Day 1 of culture, i.e. following attachment, $24 \mathrm{~h}$ after plating, incubation with $10 \mathrm{mmol}$ sodium fluoride/ $\mathrm{l}$ for $1 \mathrm{~h}$ stimulated a significant release of arachidonic acid $(P<0 \cdot 01)$ from triglycerides $(P<0.02)$, but had no effect on phospholipid hydrolysis (Fig. 7). The converse was demonstrated when cells were treated on Day 2 of culture, when (Figs 6 and 7) arachidonic acid was released from phospholipids $(P<0 \cdot 01)$, but not from triglycerides. The response was demonstrated clearly in an experiment (Fig. 7) in which incubation of prelabelled stromal cells with $10 \mathrm{mmol}$ sodium fluoride/l for $60 \mathrm{~min}$ stimulated a $6 \%$ increase in arachidonic acid release above the basal value of $17 \%(P<0.01)$. In this experiment, the released arachidonic acid originated from both phosphatidylinositol and phosphatidylcholine.

Calcium ionophore $(10 \mu \mathrm{mol} / 1)$, which was included in these experiments for comparison, had no effect on arachidonic acid release on either Day 1 or 2 of culture.

Endometrial glands in culture. Incubation of endometrial glands with sodium fluoride on both Days 1 and 2 of culture stimulated a significant release of arachidonic acid $(P<0 \cdot 01)$ from 

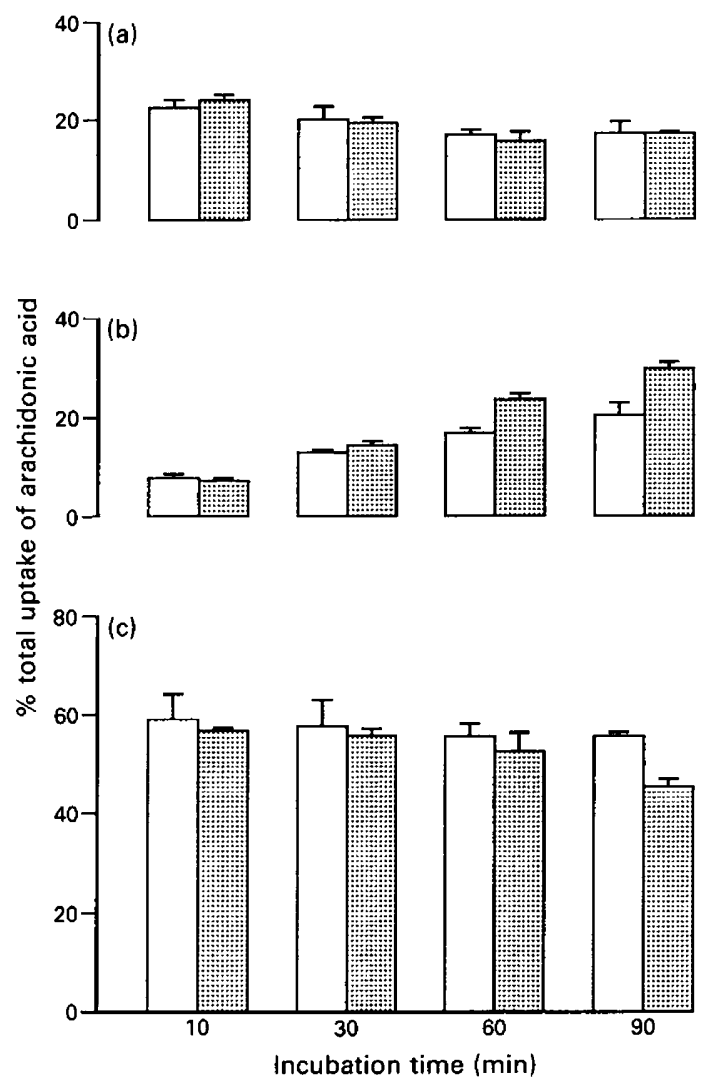

Fig. 6. Effect of incubation time on the release of $\left[{ }^{14} \mathrm{C}\right]$-arachidonic acid from prelabelled human endometrial stromal cells in culture. The cells were incubated in the absence $(\square)$ or presence (圈) of $10 \mu \mathrm{mol}$ sodium fluoride/l. Uptake into (a) triglycerides and (c) phospholipids and (b) release of free arachidonic acid is expressed as \% total $\left[{ }^{14} \mathrm{C}\right]$-arachidonic acid incorporated during a 4 -h prelabelling period. Each bar represents the mean \pm s.d. of 4 replicates.

phospholipids, but not from triglycerides (Fig. 8). As indicated in this experiment and in those depicted in Figs 3-5, a similar response was obtained with calcium ionophore, although the release on Day 2 was greater than that in response to sodium fluoride. As in experiments described earlier, the major phospholipids contributing free arachidonic acid were phosphatidylcholine and phosphatidylinositol.

\section{Discussion}

The major targets for the incorporation of arachidonic acid into primary cultures of endometrial stromal cells are the triglyceride and phospholipid pools. In some cultures, incorporation into triglycerides may predominate (Beesley et al., 1991). In the present study, as much as $20-30 \%$ arachidonic acid was associated with the triglyceride pool. There was also a time-dependent release of arachidonic acid from triglycerides, but not from phospholipids. These findings indicate that, in stromal cells, there is a preferential turnover of the arachidonic acid stored in triglycerides. The triglyceride pool may therefore act as a temporary storage site for arachidonic acid, subsequently to 


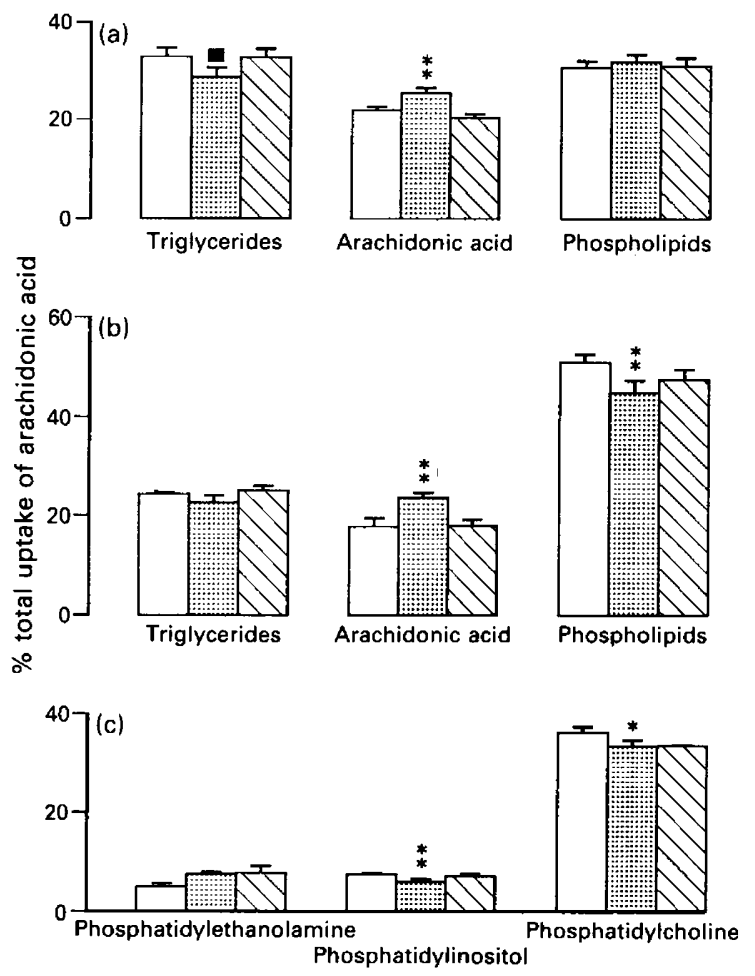

Fig. 7. Release of $\left[{ }^{14} \mathrm{C}\right]$-arachidonic acid from prelabelled human endometrial stromal cells

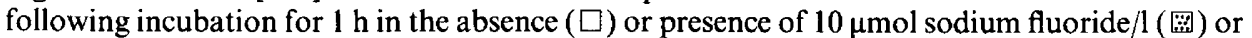
$10 \mu \mathrm{mol}$ calcium ionophore (A23187)/l ( $\mathbb{}$ ). Cells were treated after (a) 1 or (b) and (c) 2 days in culture. Uptake into triglycerides and phospholipids and release of free arachidonic acid is expressed as \% total [ $\left.{ }^{14} \mathrm{C}\right]$-arachidonic acid incorporated during a 4-h prelabelling period. Each bar represents the mean \pm s.d. of 4 replicates. ${ }^{*} P<0.05 ; \square P<0.02 ;{ }^{* *} P<0.01$.

be utilized in the synthesis and turnover of membrane phospholipids. It may also provide a readily available source of energy for a wider range of metabolic processes. Other cell types can also utilize triglycerides as a source of arachidonic acid, including human (Ragab-Thomas et al., 1987) and bovine (Denning et al., 1983) endothelial cells and the rabbit renal medulla (Liston \& Nasjletti, 1987). Our studies with human endometrial tissue fragments (Bonney et al., 1990) also support our present findings. An earlier study by Korte et al. (1983) demonstrated that, after labelling endometrial stromal cells for 2-72 h, the greater proportion of radiolabelled arachidonic acid was found in the phospholipid pool. However, the proportion of labelled triglyceride to phospholipid incorporated at $4 \mathrm{~h}$ was similar to that reported in the present study. Furthermore, our unpublished data indicate that, after labelling for $18-24 \mathrm{~h}$, most of the radioactivity is found in the phospholipid pool. The two studies are therefore similar.

In endometrial glands, in contrast to stromal cells, arachidonic acid was incorporated predominantly into phospholipids with (in most cultures) only $2-4 \%$ incorporation into triglycerides and there was no loss of arachidonic acid from this pool during subsequent timed incubations. The triglyceride pool may therefore be a less important source of free arachidonic acid in glands than in stromal cells.

Calcium ionophore is known to cause an influx of calcium ions into the cell, thereby activating $\mathrm{PLA}_{2}$ and eliciting release of arachidonic acid. Many $\mathrm{PLA}_{2}$ enzymes are calcium dependent, including PLA $_{2}$ type 1 of human endometrial glands (Bonney, 1985; Bonney et al., 1987), but PLA 2 

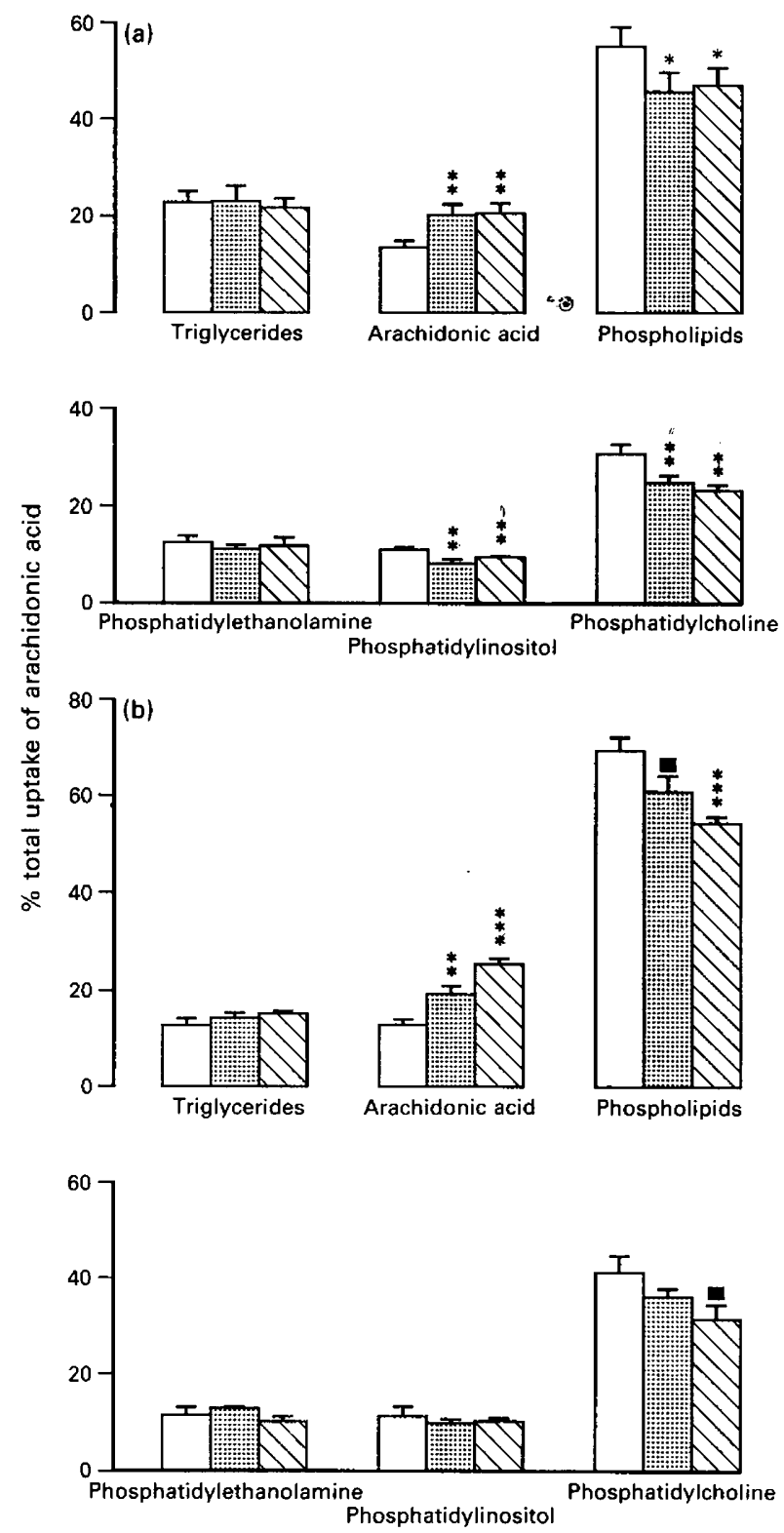

Fig. 8. Release of $\left[{ }^{14} \mathrm{C}\right]$-arachidonic acid from prelabelled human endometrial glands after incubation for $1 \mathrm{~h}$ in the absence ( $\square$ ) or presence of $10 \mu \mathrm{mol}$ sodium fluoride/l (瞵) or $10 \mu \mathrm{mol}$ calcium ionophore (A23187)/ $1(\mathbb{Q})$. Endometrial glands were treated after (a) 1 or (b) 2 days in culture. Uptake into triglycerides and phospholipids and release of free arachidonic acid is expressed as \% total $\left[{ }^{14} \mathrm{C}\right]$-arachidonic acid incorporated during a 4-h prelabelling period. Each bar represents the mean \pm s.d. of 4 replicates. ${ }^{*} P<0.05 ; \square P<0.02$; ${ }^{* *} P<0.01$; *** $P<0.001$.

type 2, present in the stromal cell component of the endometrium, is not (Bonney et al., 1987). The differences between the enzymes of the two cell types is emphasized in the present study in which calcium ionophore stimulated a marked release of arachidonic acid from endometrial glands, but had no effect on stromal cells. These results suggest that the two PLA 2 isoenzymes are activated in 
accordance with their calcium requirements, the calcium-independent PLA $\mathrm{A}_{2}$ type 2 being unresponsive to calcium ionophore. Schatz et al. (1987) demonstrated a stimulatory effect of calcium ionophore (A23187) on prostaglandin synthesis in endometrial glands, but not in stromal cells. One interpretation of their findings is that the calcium-independent PLA ${ }_{2}$ of stromal cells is unresponsive to calcium ionophore, which, consequently does not release arachidonic acid for prostaglandin synthesis.

In the present study, the main source of the arachidonic acid released from glands in response to calcium ionophore was phosphatidylcholine, but there was also some metabolism of phosphatidylinositol, particularly after the shorter stimulation of $10 \mathrm{~min}$. The hydrolysis of phosphatidylinositol by the sequential action of phospholipase C (PLC) and diacylglycerol lipase is an alternative pathway for the generation of arachidonic acid, which may be responsible in part for the release of arachidonic acid from endometrial glands. The increased incorporation of arachidonic acid into phosphatidylethanolamine with incubation time, observed in this study, may reflect some transacylation (Nijssen et al., 1986).

Guanine-nucleotide-binding proteins ( $G$ proteins) are known to be involved in numerous transmembrane signalling processes, including activation and inhibition of adenyl cyclase and the

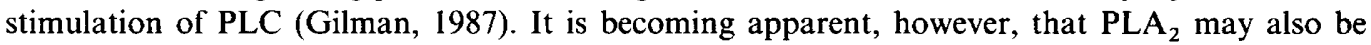
activated by signal transduction via a G-protein distinct from that involved in PLC activation (Axelrod et al., 1988). Sodium fluoride is a well-known activator of G-proteins and a useful tool with which to investigate events mediated by G-proteins. In the present study, it was shown to cause a release of arachidonic acid from both stromal cells and endometrial glands. The release of arachidonic acid from endometrial glands followed a similar pattern to that elicited by calcium ionophore and involved primarily phosphatidylcholine hydrolysis, although phosphatidylinositol was also metabolized to some extent. It is apparent, therefore, that both calcium-mediated and G-protein-mediated stimulation of arachidonic acid release can occur from endometrial glands.

Activation of arachidonic acid release from stromal cells by sodium fluoride involved the hydrolysis of both phospholipids and triglycerides. The time in culture influenced the response obtained, since in 1-day cultures, sodium fluoride induced a release of arachidonic acid from triglycerides, but not from phospholipids, whereas in 2-day cultures the reverse was the case. The release of arachidonic acid from triglycerides following a challenge with fluoride provides further evidence that triglycerides provide a temporary store of fatty acids for phospholipid turnover. The requirement for free fatty acids is likely to be greater when cells are undergoing repair and reestablishment following tissue disruption, as in newly prepared primary cell cultures and this may explain the difference in results obtained on Days 1 and 2 of culture.

The release of arachidonic acid from triglycerides by sodium fluoride suggests that the adenyl cyclase system is involved. In rabbit renal medulla, arachidonate-rich triacylglycerol is hydrolysed by a cyclic-AMP-dependent lipase (Liston \& Nasjletti, 1987) and our preliminary studies have indicated that a similar enzyme exists in human endometrium (R. C. Bonney, unpublished data).

Whether the release of arachidonic acid from phospholipids in response to fluoride ions is due to the action of PLA $\mathrm{A}_{2}$ or PLC or both is not evident from these studies since both enzymes are activated via G-proteins. However, the major phospholipid hydrolysed was phosphatidylcholine, which is generally considered to be a substrate for PLA 2 rather than for PLC. Furthermore, the contribution of diacylglycerol to the lipid content of both cell types was minimal and not altered by a challenge by either calcium ionophore or fluoride indicating that, under these conditions, activation of PLC was less important.

We gratefully acknowledge the assistance of the operating theatre staff of the Samaritan Hospital for Women, London, in supplying the tissue samples used in this study. The work was supported by grants from Birthright and St Mary's Save the Baby Fund and the Wellcome Trust. 


\section{References}

Axelrod, J., Burch, R.M. \& Jelsema, C.J. (1988) Receptor-mediated activation of phospholipase $\mathrm{A}_{2}$ via GTP-binding proteins: arachidonic acid and its metabolites as second messengers. Trends in Neurosc. 11, 117-124.

Beesley, J.S., Franks, S. \& Bonney, R.C. (1991) The steroidal regulation of arachidonic acid uptake by human endometrial stromal cells in culture. In Advances in Prostaglandin. Thromboxane and Leukotriene Research, vols $21 \mathrm{~A}$ and 21B, pp. 815818. Eds B. Samuelsson, P. W. Ramwell, R. Paoletti, G. Folco \& E. Granstrom. Raven Press, New York.

Bonney, R.C. (1985) Measurement of phospholipase $A_{2}$ activity in human endometrium during the menstrual cycle. J. Endocr. 107, 183-189.

Bonney, R.C. \& Franks, S. (1990) The endocrinology of implantation and early pregnancy. In Ballière's Clinical Endocrinology and Metabolism, vol. 4, pp. 207-231. Ed. S. Franks. Ballière Tindall, London.

Bonney, R.C., Qizilbash, S.T. \& Franks, S. (1987) Endometrial phospholipase $A_{2}$ enzymes and their regulation by steroid hormones. J. steroid Biochem. 27, 1057-1064.

Bonney, R.C., Samih, A. \& Franks, S. (1990) Uptake, distribution and release of ${ }^{3} \mathrm{H}$-arachidonic acid from human endometrium. Prostaglandins Leukot. and Essent. Fatty Acids 39, 111-117.

Denning, G.M., Figard, P.H., Kaduce, T.L. \& Spector, A.A. (1983) Role of triglycerides in endothelial cell arachidonic acid metabolism. J. Lipid Res. 24, 993-1001.

Gilman, A. (1987) G proteins: transducers of receptorgenerated signals. Ann. Rev. Biochem. 56, 615 649.
Korte, K., MacDonald, P.C., Johnston, J.M., Okita, J.R. \& Casey, M.L. (1983) Metabolism of arachidonic acid and prostanoids in human endometrial stromal cells in monolayer culture. Biochim. biophys. Acta 752, 423-433.

Liston, T. E. \& Nasjletti, A. (1987) Triacylglycerol lipase activity in the rabbit renal medulla. Biochim. biophys. Acta 921, 449-456.

Nijssen, J.G., Oosting, R.S., Nÿkamp, F.P. \& van den Bosch, H. (1986) Transfer of arachidonate from phosphatidylcholine to phosphatidyl ethanolamine and triacylglycerol in guinea pig alveolar macrophages. Lipids 21, 623-628.

Ragab-Thomas, J.M.-F., Hullin, F., Chap, H. \& DousteBlazy, L. (1987) Pathways of arachidonic acid liberation in thrombin and calciumionophore A23187. stimulated human endothelial cells: respective roles of phospholipids and triacylglycerol and evidence for diacylglycerol generation from phosphatidylcholine. Biochim. biophys. Acta 917, 388-397.

Schatz, F., Markiewicz, L. \& Gurpide, E. (1987) Differential effects of estradiol, arachidonic acid, and A23187 on prostaglandin $F_{2 \alpha}$ output by epithelial and stromal cells of human endometrium. Endocrinology 120, 1465-1471.

Vadas, P. \& Pruzanski, W. (1986) Biology of disease. Role of secretory phospholipases $A_{2}$ in the pathobiology of disease. Lab. Invest. 55, 391-404.

van den Bosch, H. (1980) Intracellular phospholipases A. Biochim. biophys. Acta 604, 191-246.

Received 8 November 1990 